Dr Zoran Ristić, pukovnik, dipl. inž. Aleksandar Kari, kapetan, dipl. inž Vojna akademija - Odsek logistike,

\section{OSCILACIJE NAGIBNOG SKLOPA ARTILJERIJSKOG ORUĐA PRI OPALJENJU}

UDC: 623.535

Rezime:

U radu su opisane oscilacije nagibnog sklopa artiljerijskog oruđa koje nastaju pri opaljenju. Nagibni sklop prikazan je kao kruto telo sa jednim stepenom slobode kretanja (rotacija u vertikalnoj ravni). Model oscilovanja uporeden je sa eksperimentalnim rezultatima realnog modela oscilovanja oruđa (oscilacije nagibnog sklopa sa više stepeni slobode kretanja). Date su razlike između proračunskog $i$ realnog modela oscilovanja $i$ analiza njihovih parametara.

Ključne reči: oscilacije, nagibni sklop, jednačina količine kretanja, slobodne oscilacije cevi, moment, usta cevi.

\title{
OSCILATION OF ELEVATING GROUP ON ARTILLERY WEAPON DURING FIRING TEST
}

\section{Summary:}

The oscillation of elevating group on artillery weapon during firing test are described in this paper. The elevation group is represented a rigid body of DOF (rotation in vertical plane). The model oscillation is compared with the experimental results of real model oscillation (oscillations of elevating group with more degrees of freedom. A difference sizes among simplify and real model oscillation are given, and some of their parameters are analyzed.

Key words: oscillation, elevation group, momentum equation, gun tube free oscillation, moment, muzzle.

\section{Uvod}

Pri opaljenju na nagibni sklop artiljerijskog oruđa deluju izrazito promenljive sile udarnog dejstva i velikog intenziteta. Trzajuća masa, kao sastavni deo nagibnog sklopa, kreće se približno pravolinijski, pri čemu istovremeno dolazi do prostornog oscilovanja sklopa kao celine. Radi proučavanja efekta promene odskočnog ugla projektila pri opaljenju, važno je posmatrati samo vertikalne oscilacije nagibnog sklopa.

Oscilacije nagibnog sklopa posmatrane su kao suma dve vrste oscilacija:

- oscilacije nagibnog sklopa kao krutog tela oko ose ramena (jednodimenzionalni model prigušenog oscilovanja krutog tela oko nepomične tačke, ali sa promenjivim položajem centra mase);

- slobodne elastične oscilacije cevi, kao najvažnijeg elementa nagibnog sklo- 
pa, nakon izletanja projektila i prestanka dejstva barutnih gasova.

\section{Oscilacije nagibnog sklopa kao krutog tela}

Za određivanje komponenti odskočnog ugla izazvanog zaokretom nagibnog sklopa, koriste se sledeće pretpostavke:

- nagibni sklop oruđa (kolevka, trzajuća masa i protivtrzajući uređaj) predstavlja apsolutno kruto telo sa konstantnim radijusom krivine;

- osa ramena, u trenutku izlaska projektila iz kanala cevi, ostaje nepokretna;

- cev sa ostalim nagibnim delovima zakreće se oko ose ramena kolevke.

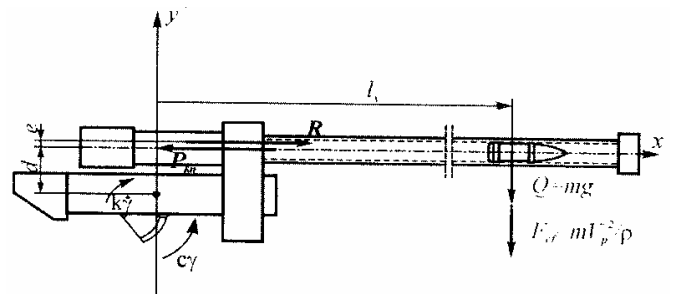

Sl. 1 - Šematski prikaz sila koje deluju na nagibni sklop pri opaljenju

Sumarni moment prikazanih sila $\mathrm{u}$ procesu opaljenja grafički je prikazan na slici 2.

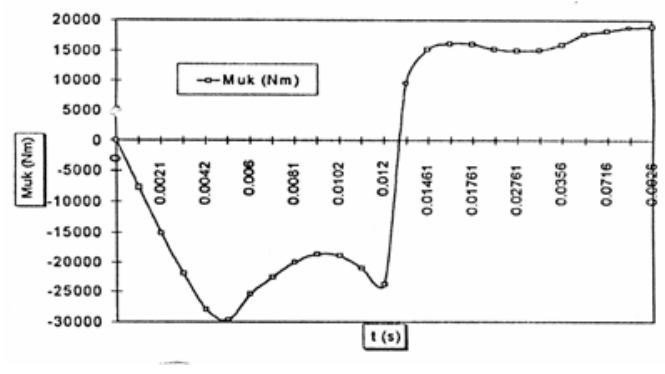

Sl. 2 - Ukupni moment u funkciji vremena
Uočava se da je nagibni sklop izložen složenom opterećenju u vrlo kratkom intervalu. Takođe, centar mase nagibnog sklopa pri opaljenju se pomera unazad (zbog kretanja trzajuće mase). Rešenje problema traži se polazeći od zakona o održanju količine kretanja koji glasi:

$$
\frac{d G_{u 0}}{d t} \sum_{i=1}^{n} M_{i}
$$

$G_{u 0}=G_{k 0}+G_{t 0}+G_{p 0}$

gde je:

$G_{k 0}$ - moment količine kretanja kolevke oko ose ramena,

$G_{t 0}-$ moment količine kretanja trzajućih delova oko ose ramena,

$G_{p 0}$ - moment količine kretanja projektila oko ose ramena kolevke.

$G_{k 0}=B_{k 0} \cdot \dot{\gamma}$

Ovde je:

$B_{k 0}$ - moment inercije kolevke za osu ramena,

$\dot{\gamma}$ - ugaona brzina zaokreta.

$G_{t 0}=\dot{\gamma} \sum \mu\left(x^{2}+y^{2}\right)+M_{T} V d$

gde su:

$\mu$ - elementarna masa trzajućih delova,

$x, y$ - koordinate elementarne mase trzajućih delova,

$M_{t}$ - ukupna masa trzajućih delova,

$V$ - brzina trzanja.

$G_{p 0}=\dot{\gamma} \sum \mu_{c}\left(x_{c}^{2}+y_{c}^{2}\right)-m V_{p}(d+e)$

gde su:

$V_{p}$ - brzina projektila u cevi, $m$ - ukupna masa projektila, 
$x_{c}, y_{c}$ - koordinate elementarne mase projektila,

$\mu_{c}$ - elementarna masa projektila.

Nakon određenih transformacija dobija se konačni oblik diferencijalne jednačine kretanja nagibnog sklopa:

$B_{u 0} \ddot{\gamma}+\left[2 \cdot\left(M_{T} V \xi-m V_{p} x_{p}\right)+k\right] \dot{\gamma}+c \gamma=$ $=-P_{k n} e+R d+Q_{T} X \cos \varphi-\frac{m V_{p}^{2}}{\rho} l_{x}-$

$-m g l_{x} \cos \varphi$

gde je:

$B_{u 0}$ - ukupan moment inercije svih delova za osu ramena,

$\xi$ - put trzanja,

$x_{p}$ - put projektila u cevi oruđa,

$P_{k n}$ - sila pritiska barutnih gasova na dno barutne komore,

$R$ - ukupna sila otpora kretanju trzajućih delova,

$\rho$-radijus zakrivljenosti cevi,

$l_{x}$ - rastojanje težišta projektila od ose ramena,

$Q_{T}$ - težina trzajućih delova,

$X$ - put težišta trzajućih delova,

$\varphi$ - ugao elevacije nagibnog sklopa,

$B_{u 0}=B_{t 0}+B_{p 0}+B_{k 0}$

gde je:

$B_{t 0}-$ moment inercije trzajućih delova za osu ramena,

$B_{p 0}$ - moment inercije projektila za osu ramena,

$B_{k 0}-$ moment inercije kolevke za osu ramena,

$$
\begin{aligned}
& B_{t 0}=B_{t t}+M_{T} r_{t t}^{2} \\
& r_{t t}^{2}=d^{2}+\left(x_{0}-\xi\right)^{2}
\end{aligned}
$$

gde je:

$x_{0}$ - položaj trzajuće mase pre opaljenja od ose ramena.

$$
\begin{aligned}
& B_{p 0}=B_{p t}+m r_{p t}^{2} \\
& r_{p t}^{2}=(d+e)^{2}+\left(x^{\prime}+x\right)^{2}
\end{aligned}
$$

gde je:

$r_{t}, r_{p t}$ - trenutna rastojanja centra mase trzajućih delova i projektila od ose ramena,

$x^{\prime}$ - položaj centra mase projektila pre opaljenja od ose ramena.

Diferencijalna jednačina (6) je oblika:

$a(t) \ddot{\gamma}+b(t) \dot{\gamma}+c(t) \gamma=d(t)$

Ona se pogodnom transformacijom svodi na sistem jednačina:

$$
\frac{d \varpi}{d t}=\frac{d(t)}{a(t)}-\frac{b(t)}{a(t)} \omega-\frac{c(t)}{a(t)} \gamma, \text { gde je } \frac{d \gamma}{d t} \omega
$$

Sistem jednačina (11) numerički je rešen na računaru metodom Runge Kuta. Kao izlazni rezultati dobijaju se ugaoni zaokreti nagibnog sklopa oko ose ramena kolevke, a samim tim i vertikalna pomeranja svake tačke duž nagibnog sklopa $\mathrm{u}$ toku vremena $Y=Y(x, t)$. To je jedna komponenta vertikalnog pomaka pri oscilovanju.

\section{Slobodne oscilacije cevi}

S obzirom na to da dejstvo pritiska barutnih gasova traje veoma kratko, a samim tim i dejstvo spoljnjeg opterećenja (nekoliko milisekundi), moguće je uvesti 
aproksimaciju da drugu komponentu oscilovanja čine slobodne oscilacije cevi kao elastičnog tela.

Cev se u prvom približenju posmatra kao konzola opterećena promenljivim momentom $M(t)=\left[R(t)-P_{k n}(t)\right] \cdot e$ i pokretnim promenljivim opterećenjem $F_{T}(t)=\frac{m V_{p}^{2}}{\rho}$.

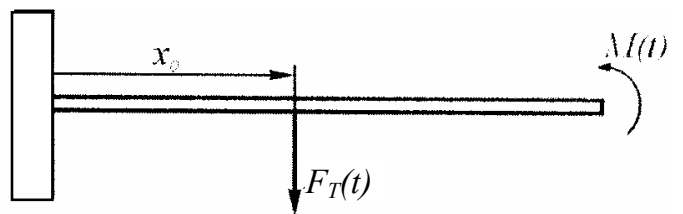

Sl. 3 -Opterećenje cevi tokom kratkog perioda

Funkcija progiba određena je analitičkim rešenjem [4] a grafički je prikazana na slici 4.

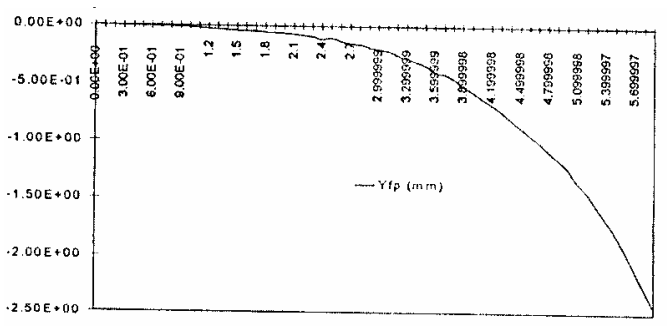

Sl. 4 - Funkcija progiba u trenutku izlaska projektila iz cevi

Prikazana funkcija predstavlja početnu veličinu progiba $\mathrm{u}$ trenutku prestanka opterećenja cevi. Cev se nadalje smatra neopterećenim elastičnim telom, a prikazana funkcija predstavlja početni uslov elastičnog oscilovanja cevi.

Parcijalna diferencijalna jednačina u tom slučaju glasi [1]:

$\frac{\partial^{2} w}{\partial t^{2}}+c^{2} \frac{\partial^{4} w}{\partial x^{4}}=0$
Početni uslovi su:

$w(x, 0)=f(x) \mathrm{i} \frac{\partial w(x, 0)}{\partial t}=0$

Rešenje je oblika:

$w(x, t)=\sum_{n=1}^{\infty} A_{n} X_{n}(x) \cos \varpi_{n} t$

gde je:

$X_{n}(x)=\frac{\mathrm{Ch} k_{n} x-\cos k_{n} x}{\operatorname{Ch} k_{n} l+\cos k_{n} l}-$

$-\frac{\operatorname{Sh} k_{n} x-\sin k_{n} x}{\operatorname{Sh} k_{n} l-\sin k_{n} l}$

$A_{n}=\frac{\int_{0}^{1} f(x) X_{n}(x) d x}{\int_{0}^{i} X_{n}^{2}(x) d x}$

Rešavanjem jednačina (14) i (15) dobiju se vrednosti elastičnog progiba svake tačke tokom vremena, što predstavlja drugu komponentu vertikalnog pomaka nagibnog sklopa artiljerijskog oruđa $\mathrm{u}$ toku procesa opaljenja (odnosno $\mathrm{u}$ toku trzanja).

Jednostavnim sabiranjem pomenutih vrednosti pomaka dobija se ukupni pomak svake tačke duž nagibnog sklopa. $\mathrm{Za}$ usta cevi ukupni pomak, u funkciji vremena, prikazan je na slici 5 .

\section{Analiza rezultata i zaključak}

Ulazne veličine pri razmatranju oscilacija artiljerijskog oruđa su promenljivi moment $M(t)$, koji deluje na kolevku 


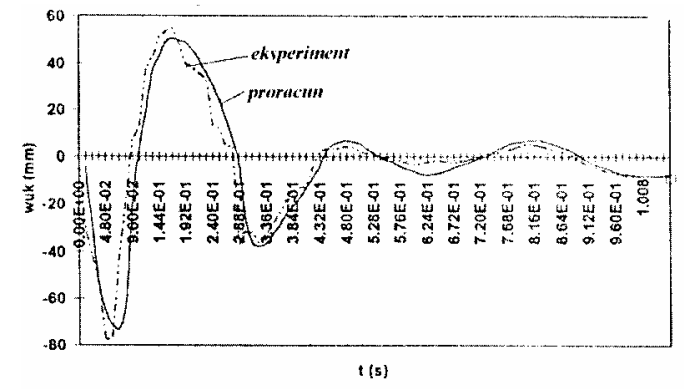

Sl. 5 - Oscilacije na ustima cevi (proračunski i eksperimentalni rezultati)

(velikog intenziteta $\mathrm{u}$ veoma kratkom vremenskom intervalu), i početni pomak $Y o(x, t)$, nakon izlaska projektila iz cevi. Kao izlazne veličine dobijaju se odstupanja $\mathrm{W}(\mathrm{x}, \mathrm{t})$. Na dijagramu na slici 5 prikazana su odstupanja na ustima cevi Wuk(1,t), kao i rezultati eksperimentalnih ispitivanja za usta cevi [3]. Sa dijagrama elongacija na ustima cevi može se zaključiti sledeće:

- u početnom periodu pomak na ustima cevi je negativan, pošto se cev, pri montaži na artiljerijsko oruđe, ugrađuje tako da joj je centar zakrivljenosti iznad ose kanala cevi, pa je centrifugalna sila koja deluje na projektil usmerena naniže, kao i zbog smera delovanja sprega $P_{k n} e$;

- u trenutku kada projektil napušta cev nestaje i centrifugalna sila koja deluje na projektil, kao i moment sprega $P_{k n}$ e. Nadalje, sistem se rešava superpozicijom prigušenog prinudnog oscilovanja krutog tela sa promenjivim položajem centra mase i slobodnog elastičnog oscilovanja;

- prikazani model oscilovanja, što se tiče vrednosti pomeranja na ustima cevi, ne odstupa značajnije u odnosu na eksperimentalne rezultate za oruđe određenog kalibra, što znači da se prikazani model proračuna može primeniti na analizu po- našanja nagibnog sklopa artiljerijskog sistema u vertikalnoj ravni pri opaljenju;

- u početnom periodu vremena, proračunska odstupanja su nešto manja od stvarnih, jer je praktično nemoguće $u$ potpunosti simulirati izuzetno velike sile i momente koji deluju na nagibni sklop tokom dejstva barutnih gasova (radi se o udarnom opterećenju). Stvarno dejstvo momenta u tom periodu nešto je veće od proračunatog. U završnoj fazi proračunska odstupanja su nešto veća od stvarnih zbog usvojenog idealiziranog modela slobodnih elastičnih oscilacija, kao i zbog zanemarenja dejstva sile ukupnog otpora $\mathrm{R}$ u tom periodu, koja prigušuje sistem;

- analizom vremenskog odziva zaključuje se da je u proračunskom modelu došlo do malog pozitivnog pomaka $u$ fazi u odnosu na eksperimentalni model, pošto su u proračunu zanemareni odzivi nekih elemenata u nizu, koji osciluju pri oscilovanju nagibnog sklopa (sistemi zupčanika, elementi PT sistema i sl.);

- pošto su odstupanja proračunskog modela manja od $10 \% \mathrm{u}$ odnosu na ona dobijena eksperimentom, znači da se ovaj model može primeniti za analizu parametara koji utiču na nagibni sklop artiljerijskog sistema pri opaljenju (promena konstrukcionih veličina i sl.). Dalji rad mogao bi biti usmeren u tom pravcu radi optimizacije konstrukcije nagibnog sklopa.

Literatura:

[1] Radosavljević, Lj.: Teorija oscilacija, Beograd, 1981.

[2] Ristić, Z.: Kretanje trzajuće mase oruđa pri trzanju, CVTŠ, Zagreb, 1989.

[3] Kalezić, M.: Optimizacija konstrukcije art. sistema na bazi fenomena procesa lansiranja projektila, doktorska disertacija, Beograd, 1993.

[4] Landau, L. D.; Lifšic, E. M.: Teoretičeskaja fizika - Tom I, Moskva, 1973.

[5] Orlov, B.; Larman, Maukov: Ustroistvo i proektirovanie stvolov artilerijskih orudij, Mašinostroenie, Moskva, 1976. 